\title{
European Association of Archaeologists 25 years: Beyond paradigms
}

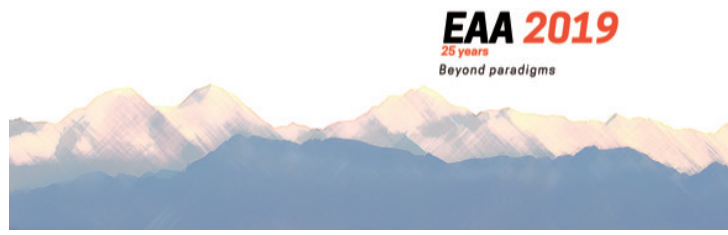

Sophie Hüglin' 1 A. Alterauge ${ }^{2}$ and A. Hafner ${ }^{2}$

Bern, Switzerland, 4-7 September 2019

The European Association of Archaeologists (EAA; e-a-a.org/eaa2019) met in Bern to hold its 25th Annual Meeting under the motto "Beyond paradigms" (Criado-Boado and Hüglin 2019). EAA currently has more than 2500 members from more than 50 countries of which more than 1800 took part in this year's conference. The six themes of the conference reached from "Global Change and Archaeology" to "Digital Archaeology, Science and Multidisciplinarity". Each of the themes not only received the attention of several sessions, but was also addressed by a keynote lecture. Due to the high number of sessions (166) and presentations - this year over 1500 - there were more than 30 parallel sessions. Thanks to the local hosts, Albert Hafner and Amelie Alterauge, and to the EAA Secretariat from Prague, the meeting ran exceptionally smoothly.

The theme "Archaeology of Mountainous Landscapes" was specifically connected with Switzerland and the Alps. Linked to this theme, the current president of Swiss Archaeology, Thomas Reitmaier, led a four-day "Grand Tour to the Archaeology of Mountainous Landscapes". Like all other excursions it was expertly organized by ArchaeoConcept and all tours were fully booked. The keynote lecture dedicated to the theme, delivered by Francesco Carrer, was entitled "Aiming High: The rise of mountain archaeology and its role in today's changing world". Another thematic focus in Bern was archaeoastronomy through the cooperation with SEAC (European Society for Astronomy in Culture), which organized a keynote, three sessions, and a round table. Finally, all keynote presentations and talks from more than 50 sessions will be available online on EAA's YouTube channel.

Linked to this Annual Meeting, PAGES, represented by its executive director Marie France Loutre, acted as a co-organizer of the scientific program. PAGES hosted a flyer table in the exhibition tent "Archaeology in Switzerland" where the institutions that supported the local organizers in strategic, financial or practical ways had the opportunity to exhibit their work. In total, six institutions provided information and publications for the public. The exhibition tent was an addition to the European Archaeology Fair (EAF). At more than 25 stands, a range of publishers presented their new publications, and several other organizations and companies demonstrated the latest technologies in archaeological research. PAGES members Ariane Burke and Basil Davis convened session \#317 "Celebrating 25 Years of

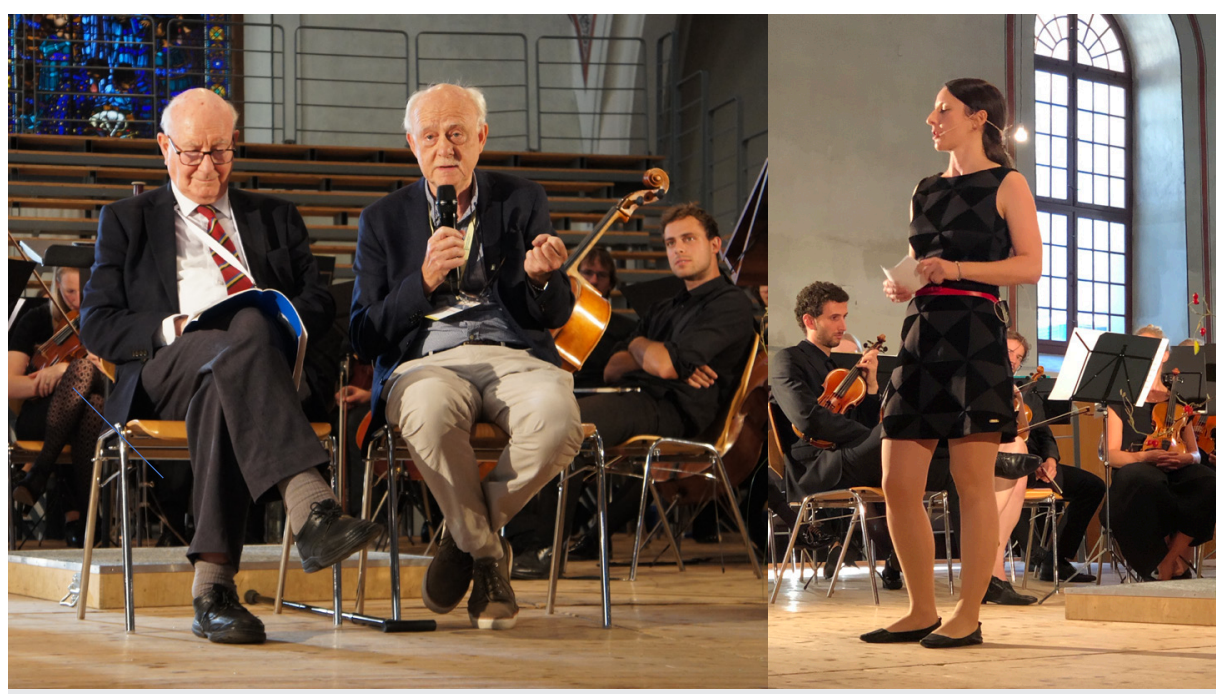

Figure 1: The entertaining opening ceremony in the French Church featured a dialogue between Colin Renfrew (left) and Kristian Kristiansen (middle) on the founding of EAA 25 years ago, and a keynote by Caroline Heitz (right), representing the generation that will shape EAA in the 25 years to come (Photos: Katka Kleinova and Sophie Hüglin).
Collaboration: How archaeology and the Earth sciences are coming together to solve real-world problems".

It should be mentioned that the EAA aims to be more than a platform for academic research and networking, but also wants to encourage archaeologists to engage in society and take social responsibility. Therefore, at each meeting an EAA Task Force works on a formal statement that addresses pressing issues. In 2019, at the Annual Members Business Meeting, the EAA adopted the "Bern Statement: Archaeology and the Future of Democracy" (e-a-a.org/BernStatement). The statement emphasizes that: "Archaeologists within EAA will not accept any form of a political use of history for propaganda purposes, especially where archaeological issues are taken out of the context of their standard academic discourses (including scholarly debates) and used for the purposes of divisive nationalistic, anti-democratic, exclusionary or chauvinistic argument". The statement was very well received by partner organizations including Europa Nostra (europanostra.org) and is currently being translated into many European languages. National archaeological organizations are also disseminating the statement by publishing it in their journals.

The EAA will have its next Annual Meeting between 26-30 August 2020 in Budapest, Hungary, under the motto "Networking" (e-a-a.org/EAA2020/Home.aspx). The call for papers will open 18 December 2019 and close 13 February 2020. The EAA encourages all archaeologists to contribute to and participate in the conference and to follow the EAA to Kiel, Germany, in 2021 and Belfast, Northern Ireland, in 2022.

\section{AFFILIATIONS}

'European Association of Archaeologists, Prague, Czech Republic

Institute of Archaeological Sciences, University of Bern, Switzerland

\section{CONTACT}

Sophie Hüglin: vicepresident@e-a-a.org

\section{REFERENCES}

Criado-Boado F, Hüglin S (2019) Archäologie Schweiz 42: 4-15 